\title{
Hemangioendotelioma epitelial: um tumor raro com apresentação atípica
}

\section{Epithelioid Hemangioendothelioma: \\ a rare tumor with atypical presentation}

\author{
Reis M. ${ }^{1}$, Tavares A. ${ }^{1}$, Ferreira L. ${ }^{1}$, De Carvalho L. ${ }^{2}$ \\ ${ }^{1}$ Serviço de Pneumologia do Hospital Sousa Martins. Guarda (Portugal) \\ ${ }^{2}$ Serviço de Anatomia Patológica dos Hospitais da Universidade de Coimbra. Coimbra (Portugal)
}

\begin{abstract}
Epithelioid Hemangioendothelioma is a rare neoplasia, and has its origin in the vascular endothelium. It may grow in several organs and tissues. There is not any approved therapeutic scheme and the prognosis is unpredictable.

It is reported the case of a 54-year-old male patient, with the diagnosis of pulmonary epithelioid hemangioendothelioma, with atypical imaging and clinical presentation and multiple organ involvement at the time of the diagnosis. The patient did not start chemotherapy and died two months after the histological diagnosis. Due to the rarity of this neoplasia and the inexistence of approved therapeutic scheme, by reporting this case we intend to contribute to future clinical studies.
\end{abstract}

Keywords: Lung. Epithelioid Hemangioendothelioma. Angiogenesis inhibitors.

Palabras clave: Pulmón. Hemangioendotelioma epitelioide. Angiogenesis inhibitors.

\section{Introdução}

0 hemangioendotelioma epitelial (HE) é uma neoplasia rara com origem no endotélio vascular $2-4,7,8$.

A apresentação pulmonar foi descrita pela primeira vez em 1975 por Dail e Liebow, que consideraram tratar-se de uma forma intravascular de carcinoma bronquioloalveolar ${ }^{1-5,7} .0$ desenvolvimento do conhecimento na área da microscopia electrónica e imunohistoquímica permitiu determinar a sua origem endotelial ${ }^{2-4,7}$.
0 HE pode desenvolver-se em vários órgãos e tecidos tais como: pulmões, fígado, osso, cérebro, gânglios linfáticos e tecidos moles.

0 Hemangioendotelioma epitelial é mais frequente no sexo feminin $0^{4-6}, 40 \%$ dos doentes têm idade inferior a 30 anos e aproximadamente $50 \%$ dos doentes são assintomáticos na altura do diagnóstico $0^{4,5}$.

Descrevemos o caso de um doente com Hemangioendotelioma epitelial, com apresentação e evolução clinica distinta do reduzido número de casos publicados.

Figura 1. Tomografia computorizada do tórax de alta resolução: massa hilar direita que engloba a emergência do brônquio principal direito, sem plano de clivagem com a artéria pulmonar direita.

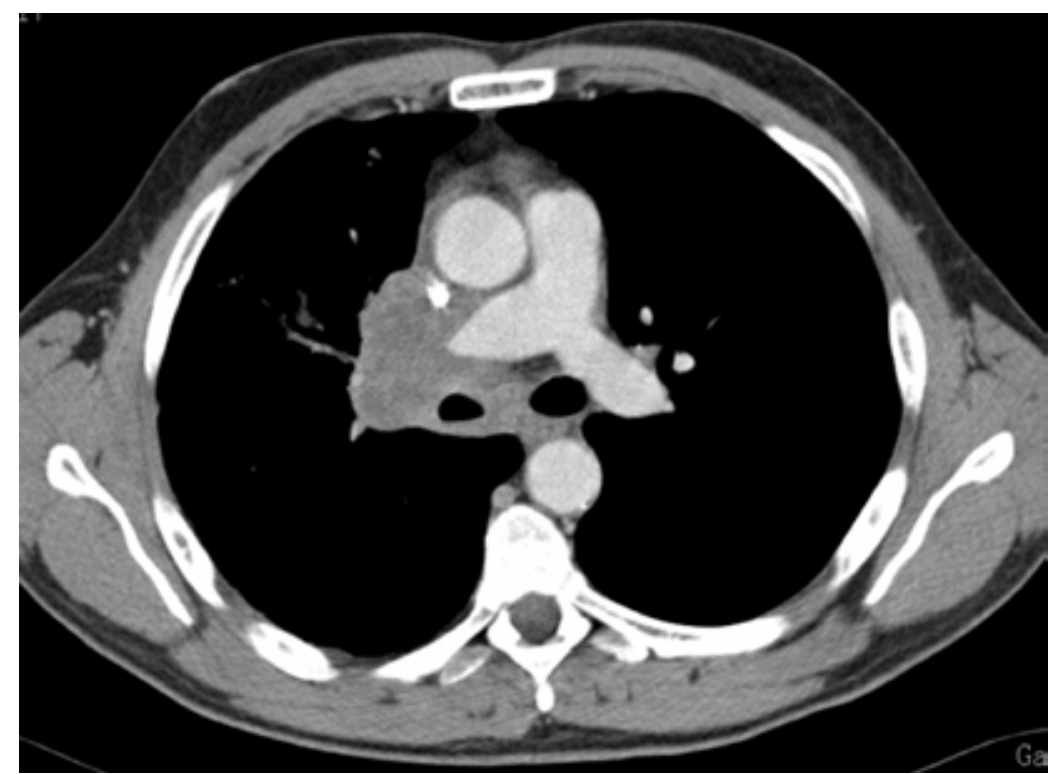




\section{Caso clínico}

Doente do sexo masculino de 54 anos de idade. Mecânico de automóveis.

0 doente apresenta antecedentes pessoais de síndrome depressivo e hipertrigliceridémia, encontrando-se medicado e com acompanhado médico regular. Trata-se de um ex-fumador com carga tabágica de 40 UMA (unidades maço ano).

Recorreu ao serviço de urgência por um quadro com 4 dias de evolução caracterizado por toracalgia anterior tipo pleurítica, localizada no terço médio do hemotórax direito, de intensidade moderada e expectoração hemoptóica com um dia de evolução.

Não apresentava alterações ao exame físico. Na radiografia do tórax observava-se hipotransparência heterogénea, de contornos irregulares, volumosa e com localização para-hilar direita, não se individualizando o hilo homolateral.

Realizou tomografia computorizada do tórax de alta resolução (TCAR) e broncofibroscopia. Na TCAR identificou-se massa hilar direita com $5.3 \times 4.8 \mathrm{~mm}$, que englobava a emergência do brônquio principal direito e do brônquio do lobo superior direito, sem plano de clivagem com a artéria pulmonar direita. Identificavam-se ainda nódulos centimétricos sub-pleurais no lobo superior do pulmão direito, adenopatias pré-carinais e pré-traqueais e nodulo de $10 \mathrm{~mm}$ na glândula supra-renal esquerda. (Figura 1). A broncofibroscopia apresentava sinais indirectos de neoplasia. Realizaram-se biópsias brônquicas proximais e escovado brônquico distal, cujo exame histológico foi inconclusivo. $\mathrm{Na}$ ecografia abdominal identificou-se lesão ecogénica de 11 $\mathrm{mm}$ no lobo direito do fígado.

Para caracterização histológica da lesão pulmonar o doente foi submetido a toracotomia para-esternal direita, com identificação de massa de consistência dura, ocupando o lobo superior do pulmão e com extensão ao mediastino. Foram realizadas biópsias.
0 doente apresentou como complicação 36 h após a cirurgia, hemotórax de moderado volume à direita.

0 exame histológico da biópsia mostrava extensas áreas de necrose, fragmento com trajecto vascular da parede, proliferação de células poligonais, vacúolos citoplasmáticos e estudo imunohistoquímico positivo para os factores VIII, CD31 e CD34, compatível com o diagnóstico de Hemangioendotelioma epitelial (Figura 2).

Para estadiamento realizou ressonância magnética (RM) torácica e tomografia com emissão de positrões (PET). Na RM torácica observa-se que a lesão tumoral circunscreve a artéria pulmonar direita, condiciona redução do lúmen da veia cava superior, contacta com a parede posterior da aorta ascendente e com a aurícula esquerda. Observa-se lesão nodular no lobo direito do fígado, hiperintensa em T2 e hipointensa em T1. A PET demonstrou hiperfixação do rádiofarmaco na massa para-hilar direita, gânglios cervicais esquerdos, supra-claviculares, pré-vasculares, pré-traqueais direitos, hilares direitos e peri-pancreático, lobo direito do fígado, glândula supra-renal esquerda, osso ilíaco direito e região glútea esquerda (Figura 3).

Três meses após o início do quadro clínico, o doente apresentou alterações do comportamento e crises epilépticas focais a nível do membro superior esquerdo. Realizou tomografia computorizada crânio-encefálica que demonstrou múltiplas lesões localizadas em ambos hemisférios cerebrais, na protuberância e no pedúnculo cerebral esquerdo. A lesão de maiores dimensões com $15 \mathrm{~mm}$ e extensa área de necrose localizava-se na região fronto-pariental direita.

0 doente efectuou 10 sessões de radioterapia holocraniana, na dose total de 80 Gy. Não iniciou quimioterapia ou outra terapêutica para além da referida. Faleceu no domicílio 4 meses após o início da sintomatologia e 2 meses após o diagnóstico histológico.

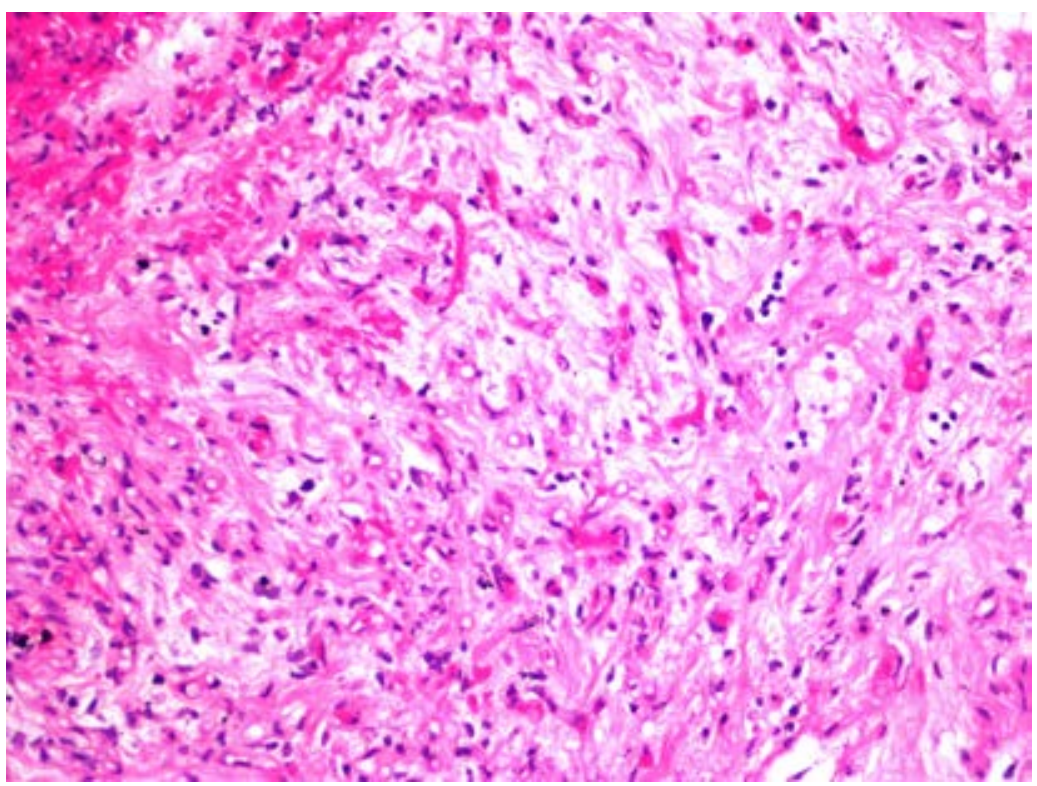


Figura 3. Tomografia com emissão de positrões: hiperfixação do rádiofarmaco em massa pulmonar para-hilar direita e lobo direito do fígado.

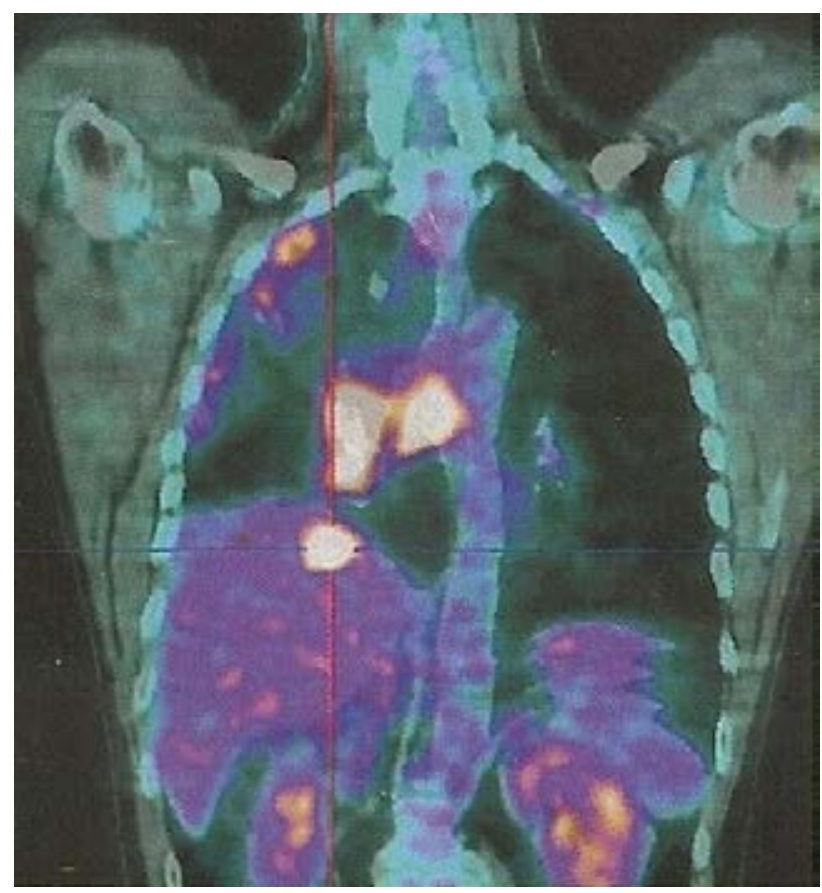

\section{Discussão}

0 HE é uma neoplasia rara ${ }^{3-5,7}$. Apresenta um grau de malignidade baixo a intermédio ${ }^{3-5,7,8}$.

Nos doentes com envolvimento de predomínio a nível pulmonar, o achado imagiológico característico é a existência de múltiplas lesões nodulares bilaterais, de tamanho inferior a $1 \mathrm{~cm}$ e com distribuição perivascular ${ }^{2,4,7}$.

0 envolvimento multiorgânico documentado nomeadamente pulmonar, hepático, ósseo, cerebral, supra-renal, ganglionar e dos tecidos moles pode dever-se a origem multiorgânica ou metastização à distância. A rápida progressão da doença não nos permitiu esclarecer a origem das lesões.

Os exames de imagem realizados não nos permitem concluir se a lesão nodular hepática se trata de um hemangioma, de uma lesão metastática ou de origem multicêntrica. 0 hemangioma geralmente apresenta-se hiperecogénico e bem delimitado no estudo ecográfico e na RM apresenta acentuado hipersinal em T2 ${ }^{6}$. As metástases hepáticas geralmente apresentam-se no estudo ecográfico como ecogénicas ou hipoecogénicas e rodeadas por um halo hipereco- génic $0^{6}$. A maioria das lesões secundárias são hiperintensas em T2 ${ }^{6}$. Para melhor caracterização da lesão hepática é importante realizar estudo hepático dirigido, não efectuado devido ao estado clinico do doente ${ }^{6}$.

No nosso caso o estudo imunohistoquímico permitiu estabelecer o diagnóstico de $\mathrm{HE}$, através da identificação de marcadores de origem vascular CD31, CD34 e factor VIII na peça cirúrgica.

Dado a raridade da neoplasia, não existe nenhum esquema terapêutico aprovado $0^{4,7}$. A ressecção cirúrgica é 0 tratamento de eleição e está indicada perante a existência de lesão única ou múltiplas lesões ressecáveis ${ }^{2,3,8}$. Estão descritos alguns casos de remissão espontânea anos após o diagnóstico ${ }^{2,4,7}$ e resposta completa após 6 ciclos de quimioterapia com Carboplatina e Etoposido $0^{4,7}$. Tendo em conta a sua origem vascular, uma terapêutica promissora é imunoterapia através da utilização de inibidores da angiogénese ${ }^{4}$. Estudos demonstram casos com resposta ao tratamento com interferão- $\alpha^{2,3,7}$

0 curso clinico e o prognóstico são imprevisíveis $4,7,8$. São factores de mau prognóstico sintomatologia respiratória na altura do diagnóstico ${ }^{2,4}$, presença de doença multicêntrica, metastização hepática ou ganglionar ${ }^{2,7}$, anemia, hemorragia alveolar e derrame pleural hemático ${ }^{8}$. A sobrevida dos casos descritos na literatura varia entre 2 e 24 anos $^{4}$

Em conclusão, o nosso caso retracta um doente com 0 diagnóstico de HE, com apresentação imagiológica atípica, envolvimento multiorgânico na altura do diagnóstico e curso clinico rapidamente progressivo e fatal.

\section{Bibliografia}

1. Dail DH, Liebow AA. Intravascular bronchioloalveolar tumor. Am J Pathol 1975; 78 : 6a-7a.

2. Kitaichi $\mathrm{M}$, Nagai $\mathrm{S}$, Nishimura $\mathrm{K}$ et al. Pulmonary epithelioid hemangioendothelioma in 21 patients, including three with partial spontaneous regression. Eur Respir $J$ 1998; 12: 89-96.

3. Okamura K, Ohshima T. A Case of Pulmonary Epithelioid Hemangioendothelioma Surviving 10 Years without Treatment. Ann Thorac Cardiovasc Surg 2010; 16: 432-435.

4. Ledson M, Convery R, Carty A, Evans C. Epithelioid haemangioendothelioma. Thorax 1999; 54:560-561.

5. Saleiro S, Barbosa M, Moura C, Almeida J, Ferreira S. Hemangioendotelioma epitelióide - Um tumor pulmonar raro. Rev Port Pneumol 2008; XIV (3): 421-425.

6. Tiferes D, D'Ippolito G. Liver neoplasms: imaging characterization. Radiol Bras. 2008; 41 (2):119-127.

7. Cronin P, Arenberg D. Pulmonary Epithelioid Hemangioendothelioma- an unusual case and a review of the literature. CHEST 2004; 125:789-792.

8. Bagan P, Hassan M. Prognostic factors and surgical indications of pulmonary epithelioid hemangioendothelioma: a review of the literature. Ann Thorac Surg 2006; 82:2010-2013 